Nevşehir Bilim ve Teknoloji Dergisi Cilt 6(2) 580-593 2017

DOI: 10.17100/nevbiltek.327148

URL: http://dx.doi.org/10.17100/nevbiltek.327148

\title{
Ağır Metallerin Tarla Şartlarında Buğday (Triticum Aestivum L.) Verimine Toksik Etkisinin Belirlenmesi
}

\author{
İlknur YURDAKUL ${ }^{1, *}$, Kadriye KALINBACAK ${ }^{2}$, Dilek TERZi ${ }^{3}$, Remzi Murat PEKER ${ }^{1}$ \\ ${ }^{I}$ Toprak Gübre ve Su Kaynakları Merkez Araştırma Enstitüsü Müdürlüğ̈̈, Ankara \\ ${ }^{2}$ Tarımsal Araştırmalar ve Politikalar Genel Müdürlüğ̈̈, Ankara \\ ${ }^{3}$ Bitkisel Üretim Genel Müdürlüğ̈̈, Ankara
}

$\ddot{O ̈ z}$

Çalışma tarla koşullarında potansiyel toksik ağır metallerden krom (Cr), kadmiyum (Cd) ve kobaltın (Co) buğday (Triticum aestivum L.) verimine etkilerinin saptanması amacıyla gerçekleştirilmiştir. Buğday bitkisinde toksik kritik derişimin belirlenmesi, ağır metal uygulamalarının toprakta DTPA ile ekstrakte olan metal miktarı ile toplam metal miktarı arasındaki ilişkinin incelenmesi ve bitkide ağır metal düzeyleri arasındaki ilişkinin belirlenmesi planlanmıştır. Deneme münavebe sisteminde tesadüf blokları deneme desenine göre, çakılı 3 tekrarlamalı ve 3 element için ayrı ayrı kurulmuştur. Denemenin ilk yılında deneme alanına $\mathrm{Cr}(0,3$, 6, $\left.9 \mathrm{~kg} \mathrm{da}^{-1}\right)$, Co $\left(0,20,40,60 \mathrm{~kg} \mathrm{da}^{-1}\right)$ ve $\mathrm{Cd}\left(0,5,10,15 \mathrm{~kg} \mathrm{da}^{-1}\right)$ bir kez uygulanmıştır. Uygulanan ağır metallerden $\mathrm{Cr}$ denemenin birinci ve ikinci buğday ekim yıllarında toksik etkide bulunarak, buğday verimini önemli ölçüde azaltırken, denemenin son yılında toksik etki göstermemiştir. Bununla yanında $\mathrm{Cd}$ ve Co uygulamaları deneme süresince buğday veriminde toksiklik açısından farklılık yaratacak düzeyde etkili olmamıştır. Çalışma sonuçları potansiyel toksik elementlerin toksik etkilerinde element farklarının, kirlilik yoğunluğunun ve bitki yetiştirme süresinin etkili olduğunu göstermektedir. Kirliliğin boyutları dikkate alınmak koşulu ile kirlenmiş alanlarda verim kaybının detaylandırılması ve ekonomik üretimin gerçekleştirilip gerçekleştirilemeyeceğinin takip edilmesi gerekmektedir.

Anahtar Kelimeler: Krom, Kobalt, Kadmiyum, Buğday (Triticum aestivum L.), Toprak.

\section{Determination of Toxic Effect of Heavy Metals on the Yield of Wheat (Triticum Aestivum L.) in Field Conditions}

\begin{abstract}
The Study has been conducted to determine the effects of potential toxic heavy metals like $\mathrm{Cr}, \mathrm{Cd}$ and $\mathrm{Co}$ on wheat (Triticum aestivum L.). In the study, it has been planned to determine the critical toxic concentration, to examine the relationship between the amount of metals extracted with DTPA from the soil with heavy metal applications and the total amounts of heavy metals and to determine the relationship between the levels of heavy metals in the plant. The experimental design in the study was fixed randomized blocks with 3 replications for each of the 3 elemnts. In the first year of the experiment, $\mathrm{Cr} / 0,3,6$ and $\left.9 \mathrm{~kg} \mathrm{da}^{-1}\right), \mathrm{Cd}(0$, 5,10 and $\left.15 \mathrm{~kg} \mathrm{da}^{-1}\right)$ and $\mathrm{Co}\left(0,20,40\right.$ and $\left.60 \mathrm{~kg} \mathrm{da}^{-1}\right)$ were applied in the experimental area. Among the heavy metals applied, $\mathrm{Cr}$ had a toxicity effect on wheat in the first and second year of the experiment and decreased the wheat yield at important levels but had no toxicity effect at the last year. On the other hand, $\mathrm{Cd}$ and $\mathrm{Co}$ applications had no significant toxicity effect to notice difference on the yield of wheat during the experiment. The results of the Study show that, the differences of the elements, the density of pollution and the duration of plant growty were important in the toxicity effects of potantial toxic elements. As a result, it is necessary to examine the details of yield loss and to control it economical production can be sustained considering the levels of pollution.
\end{abstract}

Keywords: Chrome, Cobalt, Cadmium, Wheat (Triticum aestivum L.), Soil.

"e-mail: ilknur_yurdakul@yahoo.com 


\section{Giriş}

Sanayinin gelişmesi ile artan çevre (toprak, hava ve su) kirliliği, gelişmiş ülkelerin başlıca sorunlarındandır [1]. Kirleticiler çevreye yayılımları ve canlı organizmadaki birikimleri neticesinde oluşturdukları toksiklikleri ile insan sağlığını tehdit etmektedirler [2-4]. Bu kirleticileri petrol, yağ, radyoaktif atıklar, sentetik deterjanlar, pestisitler, yapay ve doğal tarımsal gübreler, ağır metaller, bakteri ve virüs gibi hastalık yapıcı canlılar olarak gruplandırmak mümkündür. En ciddi kirleticiler arasında her ortamda bulunabilmeleri nedeniyle ağır metaller yer almaktadır. Evsel ve endüstriyel atık suların, arıtım yapılmadan, tarımsal alanlarda sulama suyu olarak kullanılması, toprak verimliliğini, bitki kalitesini, insanları ve hayvanları gıda zinciri yolu ile etkilemektedir [5-12]. Ağır metallerle kirlenmiş bölgelerde toksik maddeler süt çocuklarının çevresel tehditlerle karşılaştıkları tek nokta olan anne sütünde dahi bulunmaktadır [13].

Tarla şartlarında bitkilerin gelişimine ağır metal toksisitesinin araştırıldığ değildir. Ağır metallerin bitkiye etkilerinde bitki çeşidi, toprak özellikleri ve kontaminantların düzeyleri ile kompozisyonları önem arz etmektedir. Bu nedenlerle farklı bitkilerle değişik bölgelerde ve kirlilik etmenleri bazında çalışmaların gerçekleştirilmesinin önemi büyüktür. Bu çalışmada amaç $\mathrm{Cr}, \mathrm{Cd}$ ve Co’’n tarla koşullarında buğday verimine olan toksik etkisinin saptanmasıdır. Bunun yanısıra tarla toprağında toksik olan ağır metal miktarının, toksik kritik derişimin belirlenmesi, uygulamalarla toplam ve ekstrakte (DTPA) olan miktarlar ile bitkideki ağır metal miktarları arasındaki ilişkinin ortaya çıkarılması da planlanmıştır.

\section{Materyal ve Metot}

\subsection{Materyal}

Çalışmada bugday-nohut münavebe sistemi kullanılmıştır. Çalışmanın toprak ve bitki analizleri Toprak Gübre ve Su Kaynakları Merkez Araştırma Enstitüsü laboratuvarlarında yapılmıştır. Deneme toprağı killi tınlı, hafif tuzlu ve alkali reaksiyonlu, fazla kireçli, fosfor içeriği az, potasyum miktarı yüksek ve organik madde kapsamı düşüktür. Denemede kahverengi, kara pasa orta derecede dayanıklı buğday (Triticum aestivum L. cv. Gün 91) çeşidi kullanılmıştır [14].

\section{2. Ăğır Metallerin Özellikleri}

Toksik elementler diğer elementin bitkiye toksik etki yapmayacak ve suda eriyebilecek formlarından (potasyum kromat, $\mathrm{K}_{2} \mathrm{CrO}_{4}$; $\mathrm{kadmiyum} \mathrm{sülfat,} 3 \mathrm{CdSO}_{4} \cdot 8 \mathrm{H}_{2} \mathrm{O}$ ve kobalt sülfat, $\mathrm{CoSO}_{4} \cdot 6 \mathrm{H}_{2} \mathrm{O}$ ) seçilmiştir.

\subsection{Denemelerin Kurulması ve Yürütülmesi}

Çalışma tesadüf bloklarında, çakılı 3 tekerrürlü ve buğday-nohut münavebesi olacak şekilde kurulmuştur. Serada gerçekleştirilen ağır metallerin $(\mathrm{Cr}, \mathrm{Cd}$ ve $\mathrm{Co})$ buğday bitkisine toksikliği çalışması sonuçlarına (Cr 6.9, Cd 14.1 ve Co $73.6 \mathrm{mg} \mathrm{kg}^{-1}$ ) uygun seviyelerde ağır metal dozları oluşturulmuştur [15]. Tarlada ağır metallerin buğday bitkisine toksikliğinin ortaya konulması için dikkate alınan ağır metaller bir defaya mahsus olmak üzere ilk yıl ayrı ayrı uygulanmıştır (Cr: 0, 3, 6 ve 9; Cd: 0, 5, 10 ve 15; 
Co: 0, 20, 40 ve $\left.60 \mathrm{~kg} \mathrm{da}^{-1}\right)$. Fosforlu gübre olarak Triple Süper Fosfat (\% 42-44 $\left.\mathrm{P}_{2} \mathrm{O}_{5}\right)$, azotlu gübre olarak Amonyum Nitrat (\% 26) kullanılmıştır.

Çalışmanın gerçekleştirileceği alan toprak tavlı iken sürülmüş, ağır metaller parsel yüzeyine serpilerek karıştırılmıştır. Azotlu gübre parsel yüzeyine ekimle birlikte ve kardeşlenme başlangıcında, fosforlu gübre ise sadece ekimde deneme mibzeriyle verilmiştir. Boyutları $3.20 \mathrm{~m} \mathrm{x} 2.00 \mathrm{~m}$ olarak hazırlanan parseller, buğday hasatında kenar etkisi çıkarıldıktan sonra $2.88 \mathrm{~m}$ x $1.50 \mathrm{~m}$ alanda buğday hasatı yapılmıştır.

\subsection{Bitki Yaprak ve Toprak Örneklerinin Alınması ve Analiz Yöntemleri}

Buğday yaprakları Kacar ve İnal (2008) [16] tarafından bildirilen şekilde alınmıştır. Her parsele ait yaprak ve dane örnekleri laboratuvara getirilip $65^{\circ} \mathrm{C}$ 'de kurutularak, öğ̈̆tülmüş, bitki ve danelerin $\mathrm{HNO}_{3}+\mathrm{HClO}_{4}$ asit karışımı ile yaş yakmaları yapılarak AAS ile okumalar gerçekleştirilmiştir [16].

Toprak örnekleri her parselden 0-20 cm derinlikten özel yapılmış pirinç alaşımlı bir kürek ile [alınmış, temiz bez torbalara konularak toprak odasında elenmiş analize hazırlanmıştır [17]. Suyla doygunluk (\%), toprak reaksiyonu ve alınabilir potasyum ( $\mathrm{kg} \mathrm{K}_{2} \mathrm{O} \mathrm{da}^{-1}$ ), Richards (1954) [18] tarafindan bildirildiği şekilde tayin edilmiştir. Toplam tuz (\%) Richards (1954) [18], toplam kireç (\%) Çağlar (1949) [18], organik madde (\%) Walkleyve Black (1954) [19] tarafından tarif edildiği şekilde tayin edilmiştir. Bitki tarafından alınabilir fosfor $\left(\mathrm{kg} \mathrm{P}_{2} \mathrm{O}_{5} \mathrm{da}^{-1}\right)$ Olsen, Watanabe ve Dean (1954) [20], ağır metal ile mikro element analizleri Lindsay ve Norvell (1978) [21], tarafından bildirilen yöntemlere göre analiz edilmiştir. Toplam ağır metal analizleri yaş yakma (nitrik-perklorik asit) yapıldıktan sonra AAS kullanılarak belirlenmiştir.

\subsection{Değerlendirme Yöntemleri}

Ulrich ve Hills (1967) [22] tarafindan bildirildiği gibi ağır metallerin bitkideki toksik olan kritik seviyesini belirlemek için ürünün maksimum veriminde $\% 10^{\prime}$ luk azalmaya neden olan toksik element miktarı kullanılmıştır. Uygulanan ağır metal dozlarına göre bitki ve topraktaki ağır metal içeriklerinin kıyaslanması Mstat proğramında Anova analizi kullanılarak değerlendirilmiştir [23].

\section{Bulgular}

\subsection{Cr Uygulamasının Buğday Verimi ve Bitki Aksamı Üzerine Etkileri}

Cr uygulamasının 1. yılında buğdayın ortalama verimi $513 \mathrm{~kg} \mathrm{da}^{-1}$ değerinden $146 \mathrm{~kg} \mathrm{da}^{-1}$ değerine kadar düşerken verimdeki azalma 2. yılda $472 \mathrm{~kg} \mathrm{da}^{-1}$ değerinden $342 \mathrm{~kg} \mathrm{da}^{-1}$ değerine düşmüştür (Tablo 1, Şekil 1). Son buğday ekim yılında uygulanan Nisan ayında gerçekleşen şiddetli soğuk nedeni ile verimde genel düşüşler olmakla birlikte; ilk y1l uygulanan $\mathrm{Cr}^{\prime}$ un buğdaya toksik etkisi ortadan kalkmış, aynı parsellerde buğday veriminde artışlar oluşmaya başlamıştır. Üç buğday ekim yılında da buğday bitkisinin yaprak ve danesinde $\mathrm{Cr}$ miktarları $<1.95 \mathrm{mg} \mathrm{kg}^{-1}$ olarak bulunmuştur. Bitkide toksiklik oluştuğuna dair gözlem olarak bir değişim oluşmamıştır. Toprakta ekstrakte (DTPA) edilebilir $\mathrm{Cr}$ miktarları $<0.156 \mathrm{mg} \mathrm{kg}^{-1}$ olarak bulunmuştur. Toprakta toplam $\mathrm{Cr}$ miktarı ilk uygulama yılında ortalama değer olarak en düşük 68 , en yüksek $114 \mathrm{mg} \mathrm{kg}^{-1}$ elde edilmiştir. 
Tablo 1. Cr uygulanmış alanlarda buğday verimleri

\begin{tabular}{cccc}
\hline Uygulanan element düzeyi (Cr) & $\begin{array}{c}\text { B.yıg } \\
\left(\mathrm{kg} \mathrm{da}^{-1}\right)\end{array}$ & II:yıl & III.y1 ${ }^{*}$ \\
& 513 & 472 & 87 \\
0 & 314 & 430 & 67 \\
6 & 230 & 399 & 76 \\
9 & 146 & 342 & 131 \\
$\mathrm{p}$ & $<0.01$ & $<0.01$ & $<0.01$ \\
\hline *. Nisan ayında şddetli soğuk gerçeklesmistir.
\end{tabular}

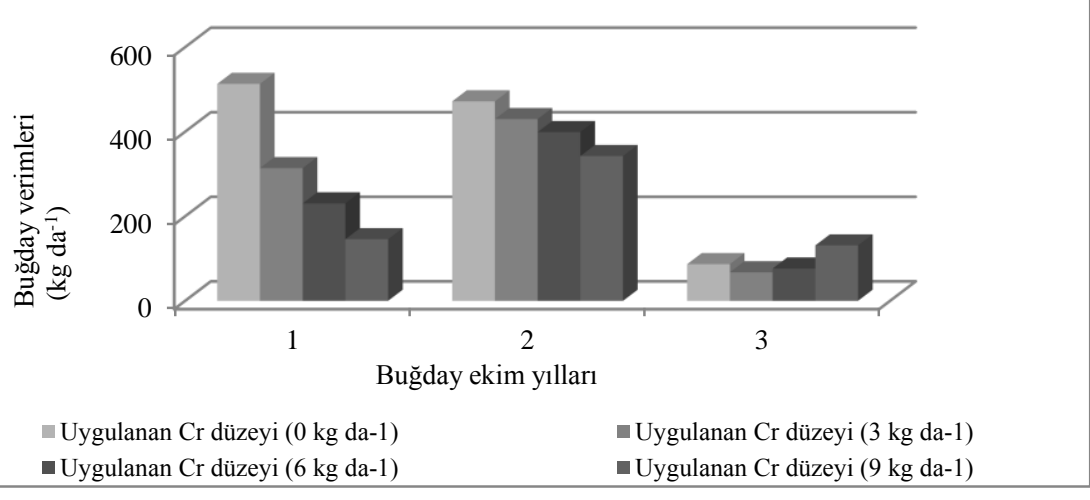

Şekil 1. Cr uygulanmış alanlarda buğday verimleri

\subsection{Cd Uygulamasının Buğday Verim ve Bitki Aksamı Üzerine Etkileri}

Buğday verimleri uygulanan Cd miktarlarına göre 1. ve 2. buğday ekim yıllarında önce azalmış daha sonra artmıştır. Son yılda ise verimde önce artış daha sonra azalma gerçekleşmiştir (Tablo 2, Şekil 2). Denemenin 1., 2. ve 3. ylllarında toprağa uygulanan $\mathrm{Cd}$ buğday verimlerinde ortalama olarak en düşük ve en yüksek değer olarak 483 ve 547, 394 ve 448 ile 56.67 ve $105 \mathrm{~kg} \mathrm{da}^{-1}$ değerleri elde edilmiş ve dalgalanan bir değişime neden olmuştur. Buğday yaprağının kuru maddesinde 1. 2. ve 3. buğday ekim yıllarında ortalama olarak en düşük ve en yüksek Cd miktarları 0.39 ve 1.13, 0.04 ve 1.15 ile 0.83 ve 1.50 $\mathrm{mg} \mathrm{kg}^{-1}$ olarak belirlenmiştir. Buğday danesinde ise yıllar itibari ile en düşük ve en yüksek Cd miktarları 0.32 ve $0.82,0.01$ ve 1.20 ile 0.38 ve $1.39 \mathrm{mg} \mathrm{kg}^{-1}$ olarak tespit edilmiştir (Şekil 3). Ylllar itibari ile $\mathrm{Cd}_{\text {DTPA }}$ değerleri ortalama ve en düşük ve en yüksek değer olarak 0.06 ve $23.3,0.06$ ve 27 ile 0.24 ve $20.33 \mathrm{mg} \mathrm{kg}{ }^{-1}$ değerlerinde, $\mathrm{Cd}_{\mathrm{T}}$ miktarları ise 1.6 ve $218,1.87$ ve 47.33 ile 1.6 ve $28.33 \mathrm{mg} \mathrm{kg}^{-1}$ değerlerinde elde edilmiştir (Şekil 4).

Tablo 2. Cd uygulanmış alanlarda buğday verimleri

\begin{tabular}{cccc}
\hline & & Buğday ortalama verim & \\
Uygulanan element düzeyi (Cd) & $\begin{array}{c}\text { I.y1l } \\
\left(\mathrm{kg} \mathrm{da}^{-1}\right)\end{array}$ & II.y1l & III.y1 $^{*}$ \\
0 & 551 & 423 & 57 \\
5 & 485 & 420 & 105 \\
10 & 483 & 448 & 86 \\
15 & 547 & 394 & 80 \\
P & $<0.01$ & $<0.01$ & $<0.01$ \\
\hline *: Nisan ayında siddetli soğuk gerceklesmeistir. & & &
\end{tabular}




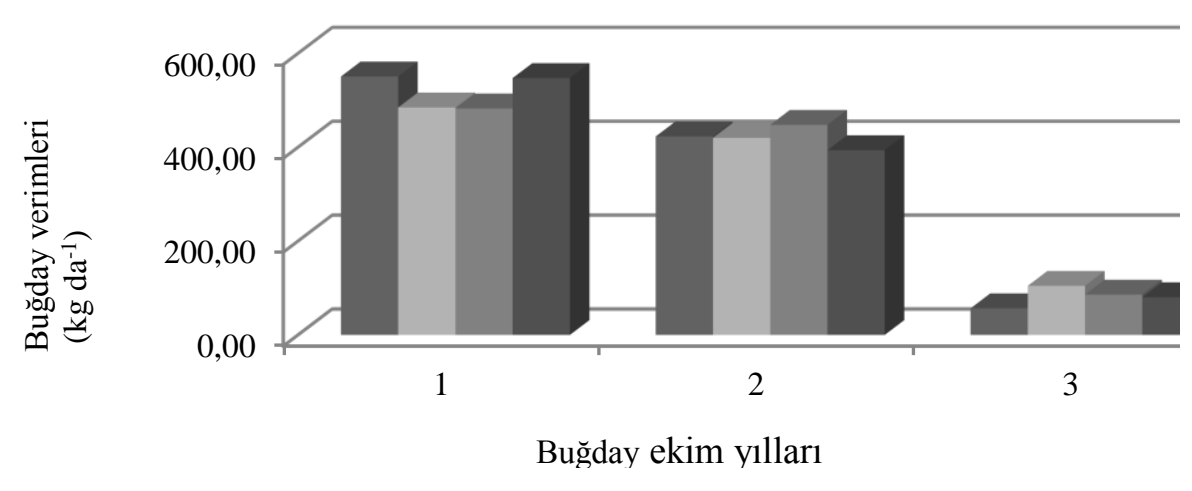

Şekil 2. Cd uygulanmış alanlarda buğday verimleri

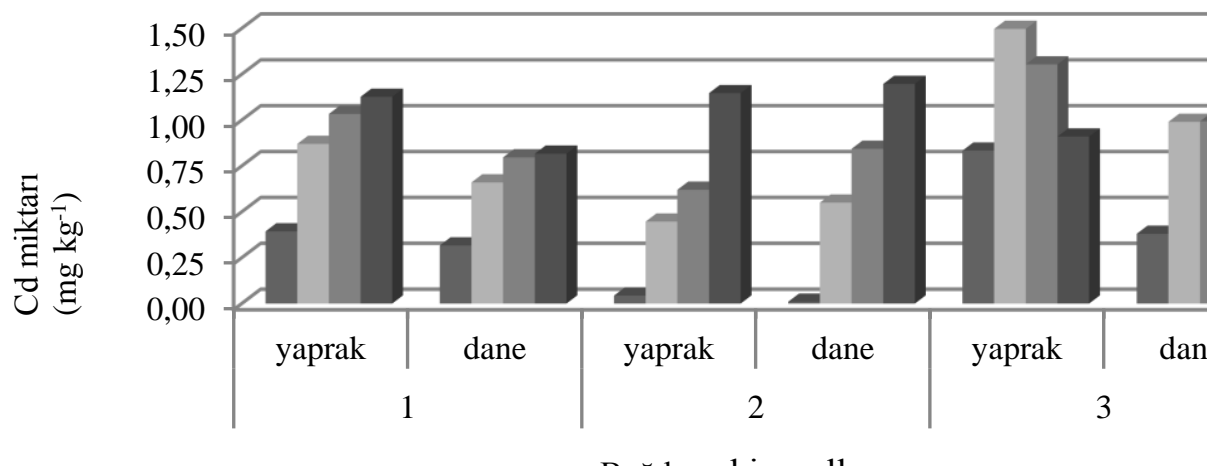

Buğday ekim yılları

Şekil 3. Buğday bitkisinin yaprak ve danesindeki Cd miktarları $\left(\mathrm{mg} \mathrm{kg}^{-1}\right)$

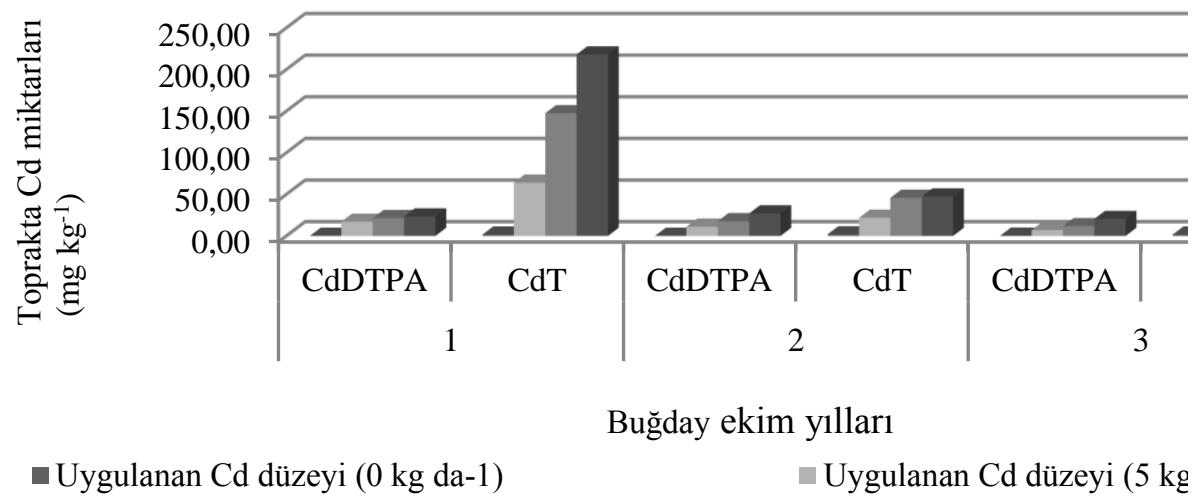

Şekil 4. Toprakta bulunan ekstrakte edilebilir ve toplam Cd miktarları

\subsection{Co Uygulamasının Buğday Verimi ve Bitki Aksamı Üzerine Etkileri}

Toprağa artan düzeylerde uygulanmış olan 20,40 ve $60 \mathrm{~kg} \mathrm{da}^{-1} \mathrm{Co}^{\prime}$ a karşıllık elde edilen buğday verimleri yıllar itibari ile ortalama en düşük ve en yüksek değer olarak 468 ve 488, 380 ve 454 ile 73 ve $96 \mathrm{~kg} \mathrm{da}^{-1}$ olarak elde edilmiştir (Tablo 3, Şekil 5). Buğday bitkisinin yaprak ve danesindeki Co düzeyleri (kuru madde) ilk yıl $<0.12$ olarak elde edilmiştir. İkinci yıl ortalama en düşük ve en yüksek değer olarak 1.59 ve 3.81 ile 3.63 ve $4.81 \mathrm{mg} \mathrm{Co} \mathrm{kg}^{-1}$ arasında; son yll ise 2.21 ve 4.07 ile 1.61 ve $4.78 \mathrm{mg} \mathrm{Co} \mathrm{kg}^{-}$ ${ }^{1}$ arasında değişen miktarlarda elde edilmiş̧tir. $\mathrm{Co}_{\text {DTPA }}$ miktarları yıllar itibari ile ortalama değer olarak en 
yüksek 56, 41.67 ve $16.33 \mathrm{mg} \mathrm{kg}^{-1}$ değerine yükselmiştir (Şekil 6, 7). Topraktaki $\mathrm{Co}_{\mathrm{T}}$ miktarı yıllar itibari ile ortalama olarak en yüksek 471, 415 ve $262 \mathrm{mg} \mathrm{kg}^{-1}$ seviyesine çıkmıştır.

Tablo 3. Co uygulanmıș alanlarda buğday verimleri $\left(\mathrm{kg} \mathrm{da}^{-1}\right)$

\begin{tabular}{cccc}
\hline & \multicolumn{3}{c}{ Buğday ortalama verim } \\
Uygulanan element düzeyi (Cd) & $\begin{array}{c}\text { I.y1l } \\
\left(\mathrm{kg} \mathrm{da}^{-1}\right)\end{array}$ & II.yıl & \\
0 & 488 & 380 & 73 \\
5 & 561 & 445 & 90 \\
10 & 512 & 454 & 86 \\
15 & 468 & 406 & 96 \\
P & $<0.01$ & $<0.01$ & $<0.01$ \\
\hline
\end{tabular}

*: Nisan ayında şiddetli soğuk gerçekleşmeiştir.

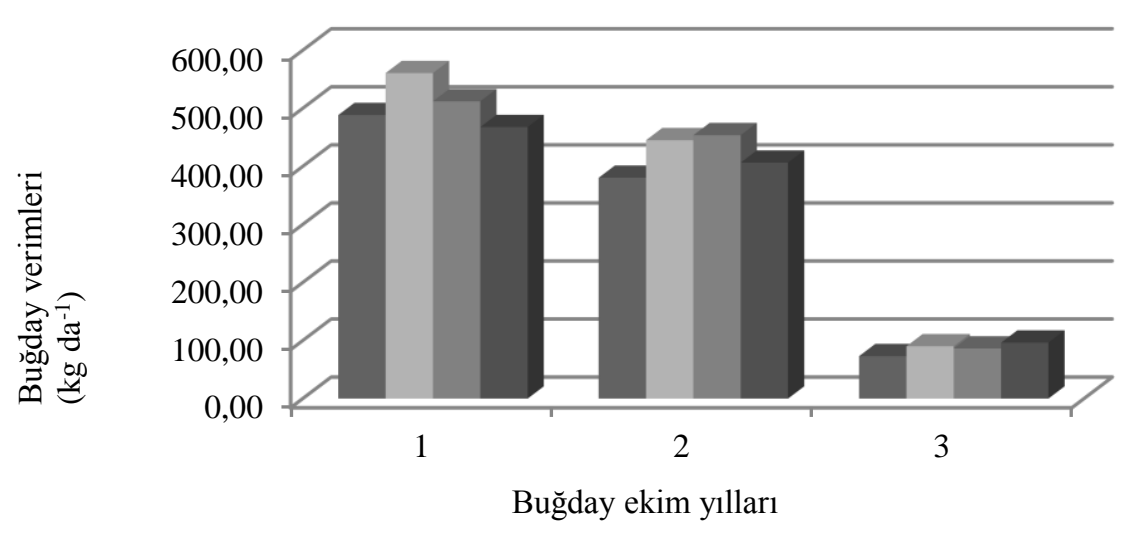

Şekil 5. Co uygulanmış alanlarda buğday verimleri $\left(\mathrm{kg} \mathrm{da}^{-1}\right)$

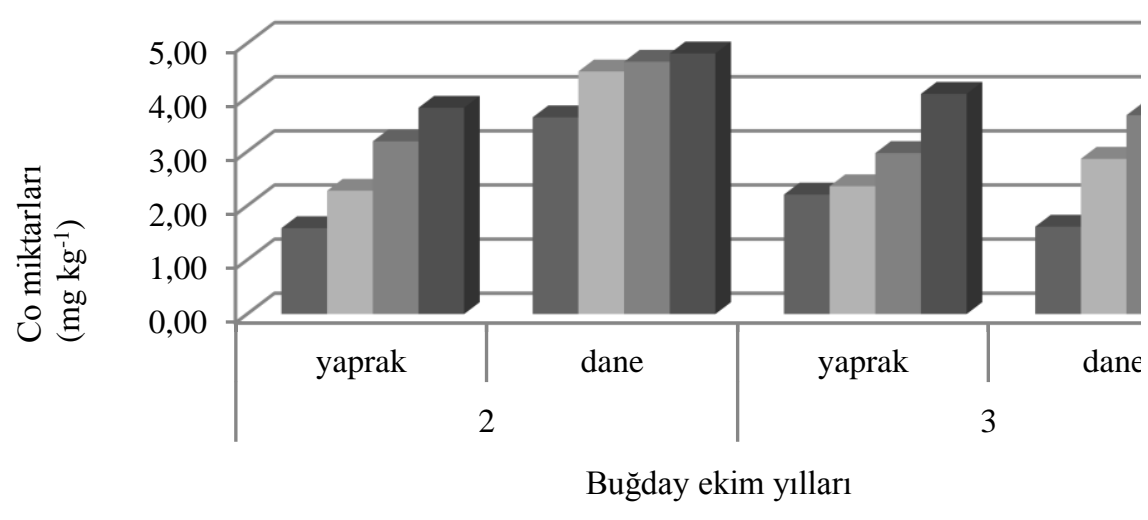

Şekil 6. Buğday bitkisinin yaprak ve danesindeki Co miktarları $\left(\mathrm{mg} \mathrm{kg}^{-1}\right)$ 


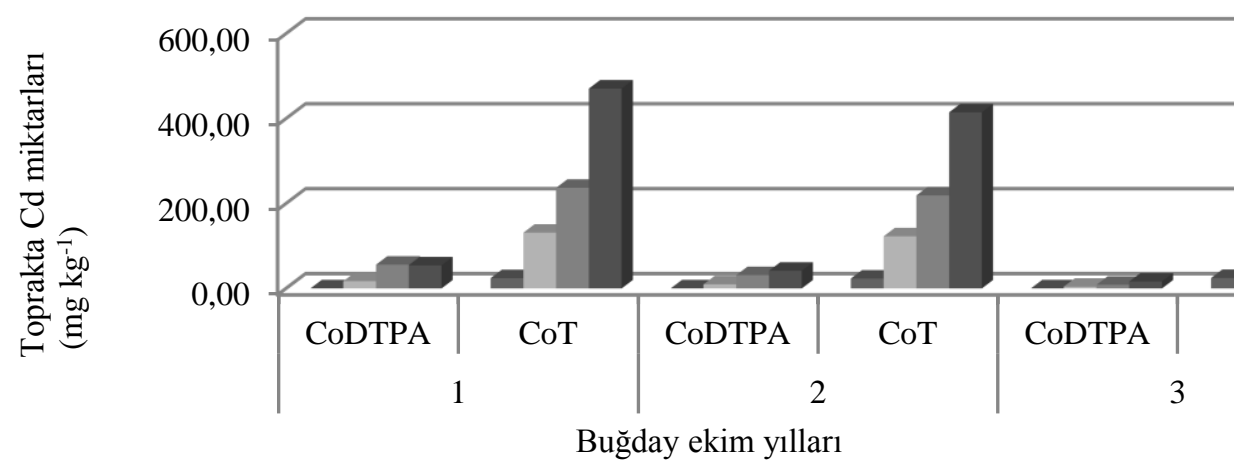

Şekil 7. Toprağa uygulanan Co düzeylerine göre topraktaki ekstrakte olan ve toplam Co miktarları (mg $\left.\mathrm{kg}^{-1}\right)$

\section{Tartışma ve Sonuç}

\subsection{Buğday Verimi Üzerine Cr Elementinin Etkisi}

Uygulanan Cr elementinin iki ekim yılında buğday verimi üzerine etkisi istatistiksel bakımdan ( $\mathrm{p}<0.01)$ önemli olmuştur. Cr uygulama düzeyleri dikkate alındığında, 1. buğday ekim yılında, maksimum verimde \%10'luk azalma (toksik $\mathrm{Cr}$ düzeyi) toprağa uygulanan Cr'un $0.69 \mathrm{~kg} \mathrm{da}{ }^{-1}$ ' $11 \mathrm{k}$ düzeyinde oluşmuştur (Şekil 8). Buğday verimleri ile topraktaki toplam $\mathrm{Cr}\left(\mathrm{Cr}_{\mathrm{T}}\right)$ miktarlarının ilişkisi istatistiksel olarak incelenmiş ve topraktaki $\mathrm{Cr}_{\mathrm{T}}$ artışı ile buğday verimindeki azalma \%1 seviyesinde $(\mathrm{p}<0.01)$ önemli olmuştur. Elde edilen maksimum buğday veriminin \%10’luk azalmayı gerçekleştiği durumda, topraktaki $\mathrm{Cr}_{\mathrm{T}}$ miktarı $78.5 \mathrm{mg} \mathrm{kg}^{-1}$ belirlenmiştir (Şekil 9). Çok düşük Cr konsantrasyonlarının dahi klorofil sentezini ve fitosentetik aktiviteyi etkilediği [24], buğday çeşitlerinde kök uzunluğunun azalmasına ve dolayısı ile verim düşüşüne neden olduğu [25], [26] ve kükürdün, biyotik ve abiyotik streslere karşı savunmada önemli bir rol oynadığ [27], bildirilmektedir. 1-10 ppm düzeylerinde Cr(VI), $\mathrm{Cu}, \mathrm{Cd}$ ve $\mathrm{Hg}(\mathrm{II})$ 'nin lahana bitkisine başbağlama zararı ile toksik etkide bulunduğunu bildirmişlerdir [28]. Kum kültüründe yazlık arpanın yaprak ve sürgünlerindeki üst kritik düzeyi kuru madde de $10 \mathrm{mg} \mathrm{Cr}$ $\mathrm{kg}^{-1} \mathrm{Cr}$ olarak tespit etmişlerdir [29]. Mısır bitki gelişiminin $5 \mathrm{mg} \mathrm{Cr} \mathrm{kg}{ }^{-1}$ olduğu durumda kısıtlandığı 50 mg Cr kg${ }^{-1}$ seviyesinde güçlü bir verim düşüşü oluştuğu bildirilmektedir [30]. Buğday danesinin sirasıyla en fazla $\mathrm{Zn}$ ve en az $\mathrm{Cr}$ metalini $(\mathrm{Zn}>\mathrm{Fe}>\mathrm{Mn}>\mathrm{Cu}>\mathrm{Pb}>\mathrm{Cd}>\mathrm{Ni}>\mathrm{Cr}$ ) bünyesinde biriktirdiği bildirilmiştir [31].

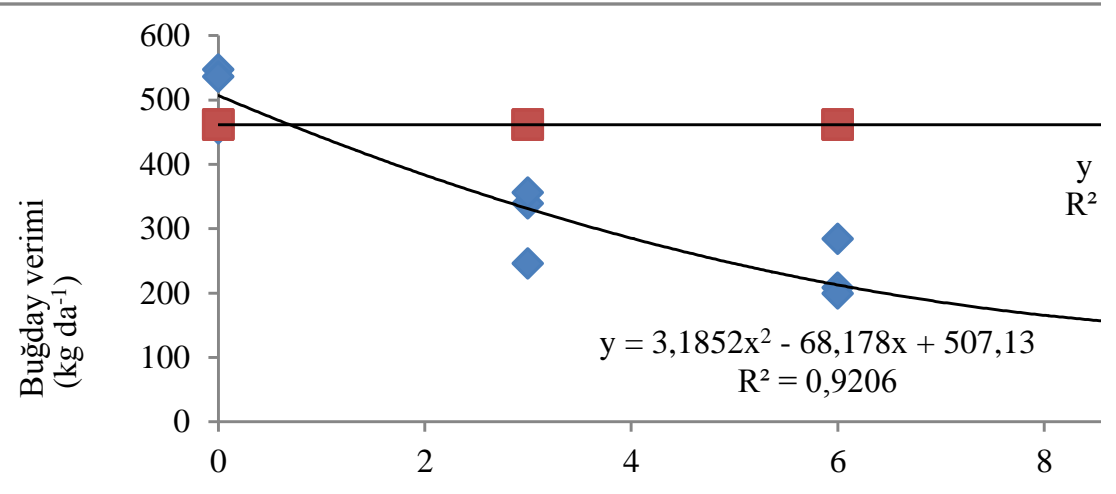

Şekil 8. Çalışmanın ilk yıl buğday verimleri ile uygulanan $\mathrm{Cr}$ ilişkisi 


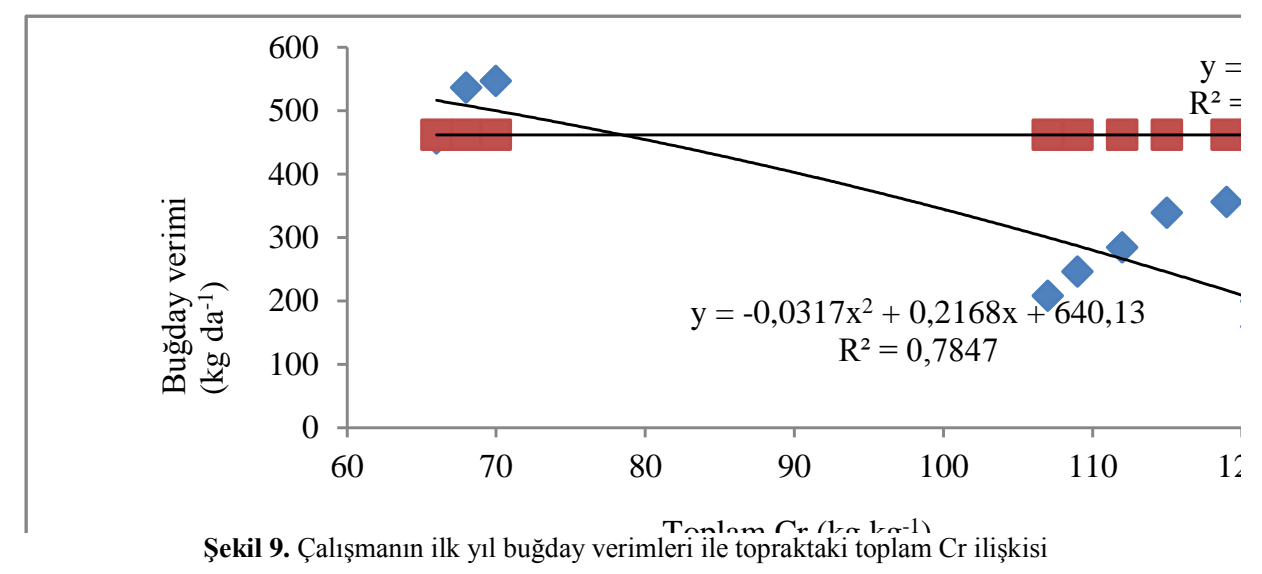

\subsection{Krom Elementinin Toksik Kritik Derişimi ile Bitki ve Toprak Üzerine Etkisi}

Üç buğday ekim yılında da buğday bitkisinin yaprak ve danesinde $\mathrm{Cr}$ miktarları $<1.95 \mathrm{mg} \mathrm{kg}^{-1}$ olarak bulunmuştur. Buğdayın üst aksamında toksik kritik derişim seviyesi oluşmamıştır. Uygulanan $\mathrm{Cr}$ ile buğday bitkisinin veriminde meydana gelen toksik etki ve verimdeki azalmanın buğday bitkisinin üst aksamından ziyade $\mathrm{Cr}$ elementinin bitkinin kök bölgesinde biriktirildiği ve bu nedenle toksik etkinin oluştuğunu düşündürmektedir. Cr'un kökten filize metal aktarım faktörünün en düşük olduğunu bildirmektedir [32]. Buğday gelişimi ve yeşil aksamın gelişimini toksik metallerin azalttığını bunun bitkinin yeşil aksamında azot eksikliği ve tahıllarda protein eksikliği olarak ortaya çıkardığı bildirilmektedir [33]. Buğdayın sürgün ve kök boyunu azaltarak bitki gelişiminin ağır metallerden olumsuz etkilendiği, kök gelişiminin etkilenmesinde ağır metal sıralamasının $\mathrm{Zn}>\mathrm{Cd}>\mathrm{Mn}>\mathrm{Cr}$ şeklinde olduğu, kök ve filizlerde olumsuz etkilenmenin aynı olduğu konsantrasyon artışı ile arttığ belirtilmektedir [34], [35]. Ağır metaller ayrıca fitolojik özellikleri etkileyerek (bitki besin maddesi alımları, fotosentez ve su ilişkiler) ve metabolik değişiklikler yaparak bitki gelişimine olumsuz etkilerde bulunmaktadır [34].

Uygulanan $\mathrm{Cr}$ miktarındaki artışa paralel olarak $\mathrm{Cr}_{\mathrm{T}}$ artış göstermiş istatistiksel $(\mathrm{p}<0.01)$ olarak önemli olmuştur. İkinci yıl ortalama değer olarak en düşük 56.3, en yüksek $68.7 \mathrm{mg} \mathrm{kg}^{-1}$ seviyelerindeki Cr miktarı azalan bir özellik göstermiş ve istatistiksel olarak önemli $(\mathrm{p}<0.01)$ olmuştur. Çalışmanın son yılında $\mathrm{Cr}_{\mathrm{T}}$ miktarları ortalama olarak en düşük 61 , en yüksek $65.3 \mathrm{mg} \mathrm{kg}^{-1}$ olarak elde edilmiştir. İstatistiksel olarak önemliliğini $(\mathrm{p}<0.05)$ artış yönünde devam ettirmiştir (Şekil 10). Atık sularla sulanan alanlarda Cr'un toksik seviyeye ulaşmadığı kökte 3.65, sapta 0.70, yaprakta 0.91 ve başakta 5.47 $\mathrm{mg} \mathrm{kg}^{-1}$ bulunduğunu [10], yüksek sicaklıkta uygulanan $\mathrm{Cr}$ ile buğday fidelerinin kök ve sürgün büyümesinin önemli ölçüde azaldığı [36], sera şartlarında toksikliğin killi ve killi tınlı toprakta 7.2 ve 6.9 $\mathrm{mg} \mathrm{kg}^{-1}$, de gerçekleştiği bildirilmiştir [37]. Karaçayırda kritik seviyenin kuru ağıllıkta $1 \mathrm{mg} \mathrm{kg}^{-1}$ olduğu bildirilmektedir [38]. 


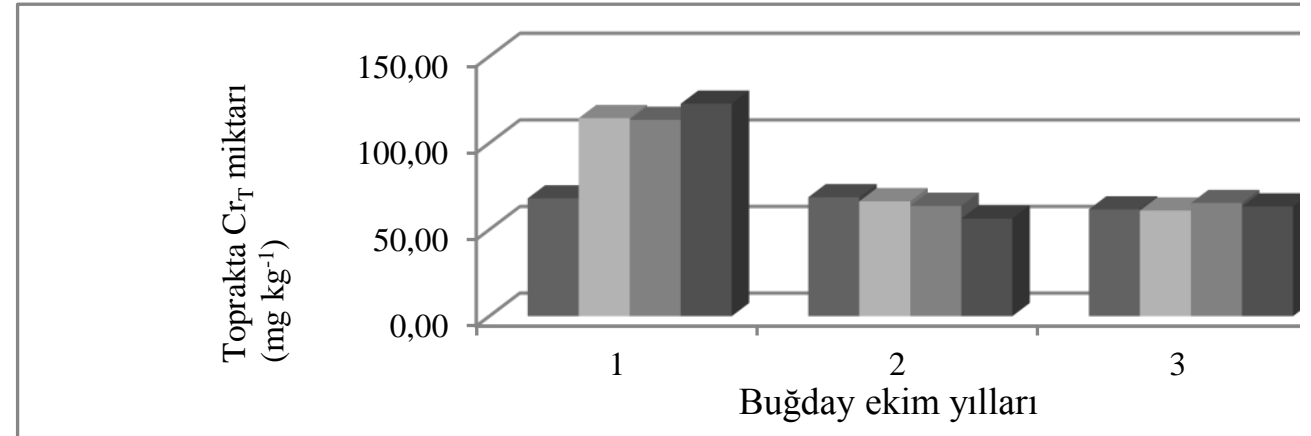

Şekil 10. Cr uygulanmış alanlarda toprakta toplam Cr miktarları

\subsection{Buğday Verimi Üzerine Cd Elementinin Etkisi}

Denemenin ilk yllında toprağa artan düzeylerde uygulanan $\mathrm{Cd}$ elementinin üç y1l içinde buğday verimine etkisi istatistiksel anlamda önemli $(\mathrm{p}<0.01)$ olmuş ancak bu önemlilik toksik etki şeklinde gelişmemiştir. [39], buğdayda $\mathrm{Ni}, \mathrm{Zn}, \mathrm{Cd}$ ve $\mathrm{Pb}$ 'un $250 \mathrm{~kg} \mathrm{ha}^{-1}$ uygulamalarının toksik etki meydana getirmediğini, toksik etkinin toprağın $\mathrm{pH}$ değerinin alkalin ve kireç içeriğinin yüksek olmasına bağlı olabileceğini ifade etmişlerdir. Toprakların Cd'u tolere edebilme yeteneklerinin toprak $\mathrm{pH}$ 's1 ve toprak taneciklerinin büyüklüğünün etkisinde olduğunu belirtmiş̧ir [40]. Besin solüsyonu ile gerçekleştirilen çalışmalarda çeşitli uygulama koşulları ve $\mathrm{Cd}$ uygulama süresine göre değişmekle birlikte Cd'un bugday çimlenme, büyüme, mineral besin maddeleri, fotosentez ve tane verimine olumsuz etkilerinin olduğu [41], buğdayın Cd stresini antioksidan enzim aktiviteerini artırarak yenmeye çalıştı̆̆ı bildirilmiştir [42].

\subsection{Kadmiyum Elementinin Toksik Kritik Derişimi, Bitki ve Toprak Üzerine Etkisi}

Uygulanan Cd miktarlarına göre buğday bitkisinin yaprağında ve danesinde kuru maddedeki $\mathrm{Cd}$ miktarları istatistiksel anlamda denemenin her üç yılında da önemli $(\mathrm{p}<0.01)$ olmuştur. Bitkinin kuru madde olarak yaprak ve danesinde Cd miktarları en fazla $1.50 \mathrm{mg} \mathrm{kg}^{-1}$ en az $1.39 \mathrm{mg} \mathrm{kg}^{-1}$ ölçülmüştür. Önceki ağır metal toksik etkisinin incelendiği çalışmalarda belirtilen $\mathrm{Cd}$ miktarlarına buğday yaprağı ve danesinde ulaşılamamıştır. Çalışmada uygulanan $\mathrm{Cd}$ için buğday veriminde toksik olan azalan bir etkide oluşmamıştır. Önceki çalışmalar üründeki \%25'lik kaybı oluşturan Cd içeriğinin buğday için 50-100 ppm olduğunu [43], bildirirken ağır metallerin tohumdan çok bitkinin diğer bölümlerinde biriktiğini [40], besin solüsyonuna Cd ilavesinin nitrat miktarın $65 \mu \mathrm{mol} \mathrm{g}^{-1} \mathrm{~h}^{-1} \mathrm{NO}_{3}$ miktarından $26 \mu \mathrm{mol} \mathrm{g}^{-1} \mathrm{~h}^{-1} \mathrm{NO}_{3}$ miktarına, potasyum miktarını $43 \mu \mathrm{mol} \mathrm{g}{ }^{-1} \mathrm{~h}^{-1} \mathrm{~K}^{+}$miktarından $19 \mu \mathrm{mol} \mathrm{g-1} \mathrm{h-1} \mathrm{K}^{+}$miktarına düşürmek sureti ile buğday gelişimini olumsuz yönde etkilediğini [44] belirtmektedir. Çalışmada yaprak ve danede, her iki dokudaki değerlerde buğday bitkisine toksik etkide bulunacak düzeyde olmamıştır. Buğday köklerinin en yüksek miktarda ağır metal bulundurduğu bunu yeşil aksamın takip ettiği en düşük miktarda ağır metalin ise tohum ve danede olduğu bildirilmektedir [45]. Buğday yapraklarındaki kararsız serbest radikal düzeyinde artan $\mathrm{Cd}$ konsantrasyonlarında anlamlı bir artış olduğu, büyük oranda dalgalanma gösterdiği ve biyokimyasal parametrelerdeki (malondialdehit içeriğinin, süperoksit dismutaz, katalaz, guaiacol peroksidaz, askorbat peroksidaz ve glutatyon redüktaz) değişikliklerin morfolojik değişiklikler oluşmadan ortaya çıkabileceği ve yönlendirici olabileceği belirtilmiştir. Buğday fidelerine oksidatif stres yaratmada Cd toksik kritik değerinin $3.3 \mathrm{mg} \mathrm{kg}^{-1}$ ile $10 \mathrm{mg} \mathrm{kg}^{-1}$ arasında olduğu bildirilmektedir [46]. 
Uygulanan $\mathrm{Cd}$ artışına göre toprakta $\mathrm{Cd}_{\mathrm{DTPA}}$ miktarı çalışmanın ilk uygulama yılında istatistiksel anlamda önemli olmuş ( $\mathrm{p}<0.05$ ) ancak devam eden yıllarda bu önemlilik devam etmemiştir (Şekil 4). Uygulamalarla topraktaki toplam Cd miktarı istatistiksel anlamda (ilk iki yıl $p<0.01$ ve son yıl $p<0.05$ ) önemli olmuştur. Uygulanan $\mathrm{Cd}$ artışı ile topraktaki $\mathrm{Cd}$ miktarlarında da artış oluşmuştur. Toprakta $\mathrm{pH}$ 7.5 olduğu durumda verimde \%10 azalmanın gerçekleştiği zaman buğday bitkisinde kuru madde de kritik seviyenin $30 \mathrm{mg} \mathrm{kg}^{-1}$ olduğu bildirilmektedir [38]. Topraktaki Cd artışı ile marul bitkisindeki Cd artı̧̧ı oluşurken [47], buğday ve kolzada kök ve filiz uzunluklarında [48], tuza duyarlı patlıcan genotiplerinde (sulama suyundaki $\mathrm{Cd}$ artışı) kök, gövde boyu ve yaprak alanı değerlerinde azalmalar meydana geldiği bildirilmiştir [49]. Fasulyenin stokinin içeriğindeki azalışa en fazla Hg etkili olurken bunu Cd'un takip ettiği bildirilmektedir [50].

\subsection{Buğday Verimi Üzerine Co Elementinin Etkisi}

Denemenin 1. 2. ve 3. buğday yıllarında toprağa Co uygulamasının buğday verimi üzerine etkisi istatistiksel olarak önemli $(\mathrm{p}<0.01)$ bulunmuştur (Şekil 5). Ancak bu önemlilik toksik etki açısından olmamış buğday veriminde artış ve azalmalarla bir dalgalanma göstermiştir. Önceki çalışma sonuçlarına göre $\mathrm{Cu}$, Co ve Cr'un buğdayın çimlenme yüzdesini azalttığı ve tohum gelişimini kısıtladığı ancak buğday çeşitlerine göre ağır metal toleransının farklılık gösterebileceği belirtilmektedir. Buğday tohumlarına 300-500 $\mathrm{mg} \mathrm{L}^{-1}$ ağır metal uygulamaları sonunda buğday kök uzunluğuna $\mathrm{Cu}$, $\mathrm{Co}$ ve $\mathrm{Cr}$ 'un fitotoksikliği \%93-95, 85-97 ve 95-96 olarak gerçekleştiği, $50 \mathrm{mg} \mathrm{L}^{-1}$ üzerindeki konsantrasyonlarda her üç elementin filiz uzunluğunda azalma meydana getirdiği bildirilmektedir [51].

\subsection{Kobalt Elementinin Toksik Kritik Derişimi, Bitki ve Toprak Üzerine Etkisi}

Toprağa uygulanan Co denemenin ilk yılında buğdayın yaprağında ve danesinde istatistiksel olarak önemli olmazken, ikinci ve üçüncü buğday ekim yıllarında $(\mathrm{p}<0.01)$ önemli olmuştur. Gerçekleşen önemlilik uygulama artışına paralel olarak buğday bitkisinin yaprağında ve danesinde artış olarak kendisini göstermiştir. Buğday bitkisinin yaprak ve danesindeki Co düzeyleri (kuru maddede) buğday bitkisinin verimini \%10 azaltacak toksik etkiyi yaratmamıştır (Şekil 9). Önceki çalışmalarda tahıllardaki toksik seviye sorgulandığında arpa için kuru maddede kritik seviye $20-25 \mathrm{mg} \mathrm{kg}^{-1}$ olarak belirlenmiştir [38]. Kontrollü şartlarda gerçekleştirilen bir çalışmada Co'ın düşük düzeylerde en az yüksek düzeylerde ise fazla toksiklik görterdiği bildirilmektedir [52].

Toprakta ekstrakte (DTPA) olan Co $\left(\mathrm{Co}_{\mathrm{DTPA}}\right)$ ile uygulanan Co arasındaki ilişki ilk iki yıl istatistiki anlamda önemli olmamış ancak son deneme yllında \%1 seviyesinde $(\mathrm{p}<0.01)$ önemli olmuştur. Uygulanan Co artışına paralel olarak toprakta $\mathrm{Co}_{\text {DTPA }}$ miktarında da artış gerçekleşmiştir. Topraktaki Co uygulamaları ile $\mathrm{Co}_{\mathrm{T}}$ miktarlarındaki artış istatistiksel olarak \%1 seviyesinde $(\mathrm{p}<0.01)$ önemli olmuştur. Kum kültüründe gerçekleştirilen çalışmalarda buğday tohumunun çimlenmesine, bitki boyuna, yaprak sayısına, yaprak genişliğine ve kuru madde miktarına $300 \mathrm{mg} \mathrm{kg}^{-1}$ üzerindeki Co uygulamalarının olumsuz etkisi olduğu bildirilmektedir [53]. Buğdayın kök, gövde, yaprak ve tohumlarında ağır metal miktarlarını tayin ettikleri çalışmalarında bitkinin ağır metal alım sıralamasının $\mathrm{Mn}>\mathrm{Zn}>\mathrm{Cu}>\mathrm{Ni}>\mathrm{Cr}>\mathrm{As}>\mathrm{Pb}>\mathrm{Cd}$ olduğunu belirterek en fazla ağır metalin bitki kökünde bulunduğunu tohumlarında en düşük miktarda ağır metal bulunduğunu bildirmişlerdir [54]. Bugdayda Co miktarları 
Norveç, İsveç ve Avustralyada düşük bulunurken (14, 18 ve 230 ppm) Kıbrısta bu değer oldukça yüksek bulunmaktadır (380 ppm) [55].

\subsection{Sonuçlar}

Toprağa çalışmanın ilk yılında uygulanan $\mathrm{Cr}$ buğday verimlerini ilk iki yılda toksik etki oluşturacak ve istatistiksel olarak önemli olacak şekilde etkilemiş, maksimum verimde \%10’luk azalma uygulanan Cr'un $0.69 \mathrm{~kg} \mathrm{da}{ }^{-1}$ 'lık düzeyinde ve topraktaki $\mathrm{Cr}_{\mathrm{T}}$ miktarının $78.5 \mathrm{mg} \mathrm{kg}^{-1}$ düzeyinde belirlenmiştir. Son yıldaki buğday verimlerinde toksik etki ortadan kalkmıştır. Çalışma alanındaki Cd ve Co uygulamalarının buğday verimine etkisi toksik olmamıştır. Toprağa uygulanan $\mathrm{Cr}$ bitki yetiştirmeye olumsuz etkisini göstermiş bulunmakta aynı zamanda da gıda zinciri ile insan/hayvan beslenmesi ile de tehlikeli olmaktadır. Kirletilmiş alanların tarımsal faaliyetler için kullanımından önce iyileştirilmesi son derece önem arz etmektedir.

\section{Kaynaklar}

[1] Karaca A., "Afşin-Elbistan termik santralı emisyonlarının çevre topraklarının fiziksel, kimyasal ve biyolojik özellikleri üzerine etkileri” Pamukkale Üniversitesi Mühendislik Fakültesi Dergisi, 7, 95-102, 2001

[2] Karaca A., Türkmen C., Arcak S., Haktanır K., Topçuoğlu B., Yıldız H., "Çayırhan termik santralı emisyonlarının yöre topraklarının bazı ağır metal ve kükürt kapsamlarına etkilerinin belirlenmesi” Ankara Üniversitesi Çevrebilimleri Dergisi, 1, 16-32,2009

[3] Gebregrekziabher B., Tesfaye S., (2014). "Asssesments of levels of lead, cadmium, cupper and zinc contamination in selected edible vegetables" International Journal of Innovation and Applied Studies, 7, 78-86, 2014

[4] Gürbüz M., Özdemir Y., “Afşin-Elbistan termik santrallerinin insan sağlığı üzerindeki etkilerinin mesafe tabanlı alg1 analizi” Türk Coğrafya Dergisi, 66, 43-50, 2016

[5] Jackson A.P., Alloway B.J., "The Transfer of Cadmium from Agricultural Soils to The Human Food Chain”, Edited by Adriado DC, Lewis Publishers, Boca Raton, 1992

[6] Marschner H., "Mineral Nutrition of Higher Plants" Academic Press, London, 1995

[7] Mclaughlin M.J., Parker D.R., Clarke J.M., "Metals and micronutrients-food safety issues" Field Crops Research, 60, 143-163, 1999

[8] Brozoska M.M., Monıuszko-Jakonıuk J., "Interactions between cadmium and zinc in the organism" Food and Chemical Toxicology, 39, 967-980, 2001

[9] Sponza D., Karaoğlu N., "Environmental geochemistry and pollution studies of Aliağa metal industry district” Environment International, 27, 541-553, 2002

[10] Karataş M., Güler E., Dursun Ş., Özdemir C., Argun M.E., "Konya ana tahliye kanalının Çengilli bölgesi tarım topraklarında ve buğdayda $\mathrm{Cu}, \mathrm{Cr}, \mathrm{Ni}$ ve $\mathrm{Pb}$ derişimlerinin belirlenmesi" Selçuk Üniversitesi Fen Edebiyat Fakültesi Fen Dergisi, 29, 91- 99, 2007

[11] Şener Ş., "Çevre için Jeoloji; Ağır Metallerin Çevresel Etkileri” Süleyman Demirel Üniversitesi Jeoloji Mühendisliğ Elektronik Dergisi, 1, 33-35, 2010 
[12] Yurdakul İ., "Kirletilmiş topraklarda ve sularda bitkisel iyileştirme teknikleri ve önemi" Türkiye Tarımsal Araştırmalar Dergisi, 2, 55-62, 2015

[13] Özçetin M., Yılmaz R., Mendil D., Koçyiğit R., Kulak Gedik D., "Presence of toxic heavy metals in human breast milk" Journal of Clinical and Analytical Medicine, 4(2), 89-92, 2013

[14] TBMAE “Tarla Bitkileri Merkez Araştırma Enstitüsü Çeşit Kataloğu” Tarla Bitkileri Merkez. Araştırma Enstitüsü Yayınları, Ankara, 2015

[15] Gedikoğlu İ., Kalınbacak K., Yalçıklı A., Yurdakul İ., "Bazı Ağır Metallerin Topraktan Ekstraksiyon Yöntemlerinin Karşılaştırılması ve Buğday Yetiştirilerek Kalibrasyonu” Toprak ve Su Kaynakları Araştırma Yıllı̆̆ 1997, Ankara, 1998

[16] Kacar B., İnal A., “Bitki Analizleri” Nobel Yayın Dă̆ıtım, Ankara, 2008

[17] Jackson M.L., “Soil Chemical Analysis” Prentice-Hall Inc, New Jersey, 1962

[18] Richards L.A., "Diagnosis and Improvement Saline and Alkaline Soils" United States Department of Agriculture, Washington, 1954

[19] Çağlar Ö., “Toprak Bilgisi” Ankara Üniversitesi Ziraat Fakültesi Yayınları, Ankara, 1949

[20] Walkley A., Black I.A., "An Examination of the Degtjareff Method for Determining Soil Organic Matter and a Proposed Modification of the Cromic Acid Titration Method" Soil Science, 37, 29-38, 1934

[21] Olsen S.R., Cole V., Watanabe F. S., Dean L.A., "Estimation of Available Phosphorus in Soils by Extraction With Sodium Bicarbonate" United States Department of Agriculture, Washington, 1954

[22] Lindsay W.L., Norvell W.A., "Development of a DTPA soil test for zinc, iron, manganese, and copper” Soil Science Society of America Journal, 42, 421-428, 1978

[23] Ulrich A., Hills F.J., "Principles and Practices of Plant Analysis. Soil Testing and Plant Analysis. Part II. Plant Analysis” Soil Science Society of America Special Publications, Washington, 1967

[24] Yurtsever N., "Deneysel İstatistik Metotlar” Köy Hizmetleri Genel Müdürlüğü Yayınları, Ankara, 1984

[25] El-Bassam N., "Spurenelemente: Nahrstoffe und Gift Zugleich” Kali-Briefe, 14, 255-272, 1978

[26] Jamal S., Iqbal N.M.Z., Athar M., "Phytotoxic effect of aluminum and chromium on the germination and early growth of wheat (Triticum aestivum) varieties Anmol and Kiran" International Journal of Enviornmental Science and Technology, 3, 411-416, 2006

[27] Shaikh I.R., Shaikh P.R., Shaikh R.A., Shaikh A.A., "International science congress association 14 phytotoxic effects of heavy metals ( $\mathrm{Cr}, \mathrm{Cd}, \mathrm{Mn}$ and $\mathrm{Zn}$ ) on wheat (Triticum aestivum L.) seed germination and seedlings growth in black cotton soil of Nanded, India" Research Journal of Chemical Sciences, 3, 14-23, 2013

[28] Rausch T., Wachter A., "Sulfur metabolism: a versatile platform for launching defence operations" Trends in Plant Science, 10, 503-509, 2005 
[29] Hara T., Sonoda Y., "Comparison of the toxicity of heavy metals to cabbage growty" Plant and Soil, 51, 127-133, 1979

[30] Davis R.D., Beckett P.H.T., Wollan E., "Critical levels of twenty potentially toxic elements in young spring barley" Plant and Soil, 49, 395-408, 1978

[31] Mossor-Pietraszewska T., "Effect of aluminium on plant metabolism" Acta Biochimica Polonica, 48, 673-686, 1978

[32] Nawaz Ul H., Qaisar M., Amir W., Muhammad I., Faridullah, Arshad P., "Assessment of heavy metals in wheat plants irrigated with contaminated wastewater" Polish Journal of Environmental Studies, 22, 115-123, 2013

[33] Singh R., Singh D.P., Kumar N., Bhargava S.K., Barman S.C., "Accumulation and translocation of heavy metals in soil and plants from fly ash contaminated area" Journal Environmental Biology, 31, 421-30, 2010

[34] Rana A., Masood A., ,'Heavy metal toxicity: Effect on plant growth and metal uptake by wheat, and on free living azotobacter" Water, Air, and Soil Pollution, 138, 165-180, 2002

[35] Shanker A.K., Carlos Cervantes C., Loza-Tavera H., Avudainayagam S., "Chromium toxicity in plants" Environment International, 31, 739-753, 2005

[36] Isak R.S., Parveen R.S., Rafique A.S., Alamgir A.S., "Phytotoxic effects of Heavy metals (Cr, $\mathrm{Cd}, \mathrm{Mn}$ and $\mathrm{Zn}$ ) on Wheat (Triticum aestivum L.) Seed Germination and Seedlings growth in Black Cotton Soil of Nanded, India” Research Journal of Chemical Sciences, 3, 14-23, 2013

[37] Ergün N., Mutlu A., Özçubukçu S., "Sıcaklık-ağır metal ( $\mathrm{Cr}$ ve $\mathrm{Cu})$ etkileşimlerinin buğday fidelerinde büyüme ve katalaz aktivitesi üzerine etkileri” Cumhuriyet Üniversitesi Fen Fakültesi Fen Bilimleri Dergisi, 32, 16-24, 2011

[38] Gedikoğlu İ., Kalınbacak K., Yalçıklı A., Yurdakul İ., "Bazı Ağır Metallerin Topraktan Ekstarsiyon Yöntemlerinin Karşılaştırılması ve Buğday Yetiştirilerek Kalibrasyonu” Köy Hizmetleri Genel Müdürlüğü Yayınları, Ankara, 1998

[39] Şener S., Gedikoğlu İ., Bilgin N., Güngör H., Üstün H., “Çeşitli Etkenlerle Kirlenen Sulama Sularının Toprak Özelliklerine ve Bitki Verimine Etkisi” Köy Hizmetleri Genel Müdürlüğü Yayınlarl, Ankara, 1994

[40] Mamata M., Rajani K.S., Sanjat K.S., Rabindra N.P., "Growth, yield and elements content of wheat (Triticum aestivum) grown in composted municipal solid wastes amended soil" Environment, Development and Sustainability, 11, 115-126, 2009

[41] A. Andersson A., Nilsson K.O., "Influence of lime and soil pH on Cd availability to plants" Ambio, 3, 198-200, 1974

[42] Rizwan M., Ali S., Abbas T., Zia-Ur-Rehman M., Hannan F., Keller C., Al-Wabel M.I., Ok Y.S., "Cadmium minimization in wheat: A critical review" Ecotoxicology and Environmental Safety, $130,43-53,2016$

[43] Kavita Y., Singh N.B., "Effects of benzoic acid and cadmium toxicity on wheat seedlings" Chilean Journal of Agricultural Research, 73, 0718-5839, 2013 
[44] Bingham F.T., Page A.L., Majler R. J., Ganje T., "Growty and cadmium accumulation of plants grown on a soil treated with a cadmium enriched sewage sludge" Journal of Environmental Quality, 4, 207-210, 1975

[45] Veselov D., Kudoyarova G., Symonyan M., Veselov S., "Effect of cadmium on ion uptake, transpiration and cytokinin content in wheat seedlings" Bulgarian Journal of Plant Physiology, Special Issue, 353-359, 2003

[46] Al-Othman Z.A., Ali R., Al-Othman A.M., Ali J., “Assessment of toxic metals in wheat crops grown on selected soils, irrigated by different water sources" Arabian Journal of Chemistry, 9, 1555-1562, 2016

[47] Renzhang L., Xiaorong W., Yi .L, Wenchao D., Hongyan G., Daqiang Y., "Effects of soil cadmium on growth, oxidative stress and antioxidant system in wheat seedlings (Triticum aestivum L)" Chemosphere, 69, 89-98, 2007

[48] Moyo D.Z., Chimbira C., "The effect of single and mixed treatments of lead and cadmium on soil bioavailability, uptake and yield of lactuca sativa irrigated with sewage effluent under green house conditions" American-Eurasian Journal Agricultural \& Enviroment Science, 6, 526531,2009

[49] Moosavi S.A., Gharineh M.H., Afshari R.T., Ebrahimi A., "Effects of some heavy metals on seed germination characteristics of canola (Barassica napus), wheat (Triticum aestivum) and safflower (Carthamus tinctorious) to evaluate phytoremediation potential of these crops" Journal of Agricultural Science, 4, 11-19, 2012

[50] Kıran S., Özkay F., Kuşvuran Ş., Ellialtığlu Ş.Ş., “Ağır metal içeriği yüksek sularla sulanan patlıcan bitkilerine uygulanan humik asidin bazı morfolojik, fizyolojik ve biyokimyasal özelliklerüzerine etkisi” Türk Tarım - Gıda Bilim ve Teknoloji Dergisi, 2, 280-288, 2014

[51] Zengin F.K., Munzuroğlu Ö., "Effects of lead $\left(\mathrm{Pb}^{++}\right)$and copper $\left(\mathrm{Cu}^{++}\right)$on the growth of root, shoot and leaf of bean (Phaseolus Vulgaris L.) seedlings" Gazi University Journal of Science, $17,1-10,2004$

[52] Gang A., Vyas A., Vyas H., "Toxic effect of heavy metals on germination and seedling growth of wheat" Journal of Environmental Research and Development, 8, 206-213, 2013

[53] Kassim J.K., Kareem M.I., Mohammed Z. K., "Nickel, Co, Cr, and Mn metals uptake by wheat and grass plants from serpentinitic soils of Penjwin, Kurdistan Rregion-Iraq" Internetional Journal of Plant Animal and Environmental Sciences, 3, 76-84, 2013

[54] Banashree S., Prema D., Nirmali G., Yendrembam M.D., "Effects of cobalt induced stress on triticum aestivum 1. crop.” Asian Journal of Agriculture and Biolog, 2, 137-147, 2014

[55] Al-Othman Z.A., Ali R., Al-Othman A.M., Ali J., Habila M.A., “Assessment of toxic metals in wheat crops grown on selected soils, irrigated by different water sources" Arabian Journal of Chemistry, 9, 1555-1562, 2016

[56] Kabata-Pendias A., "Trace Elements in Soils and Plants (Fourth Edition)", CRC Press, Taylor and Francis Group, Boca Raton, 2011 